\title{
Social class and university graduates' overqualification: testing two mediated relationships
}

\author{
González-Romá, Vicente ${ }^{a, b}$; Hernández, Ana ${ }^{a, b}$;Gamboa, Juan P. ${ }^{b}$ and Tomás, Inés ${ }^{\text {a }}$ \\ ${ }^{\mathrm{a} I D O C A L, ~ U n i v e r s i t y ~ o f ~ V a l e ̀ n c i a, ~ S p a i n, ~}{ }^{\mathrm{b}} \mathrm{OPAL}$, Universitat de València, Spain
}

\begin{abstract}
University graduates' overqualification (i.e., having more education, qualification and/or skills than one's job requires) has important negative consequences. However, much less is known about its antecedents. This represents an important gap in the literature. In order to fill this gap, the goal of this study is to test a mediational model on the antecedents of university graduates' overqualification (OQ). We posit that social class is negatively related to $O Q$ through two mediational links: a) via social capital, and $b$ ) via social capital and tolerance towards $O Q$. The results obtained in a sample of 144 university graduates provided support for the second mediational link, so that social class was positively related to social capital, which in turn was negatively related to tolerance towards $O Q$, which in turn was positively related to graduates' $O Q$. The results obtained uncover some of the antecedents of $O Q$ and suggest that increasing social capital may be a way to decrease graduates' $O Q$.
\end{abstract}

Keywords: overqualification; social class; social capital; tolerance towards overqualification

This work was supported by the Spanish Ministry of Economy and Competitiveness and the Spanish Research Agency [PSI2013-47195-R] 


\section{Introduction}

Overqualification (OQ) (i.e., having more education, qualification and/or skills than one's job requires; Maynard et al., 2006) has negative effects for individuals, organizations and society (e.g. Bolino \& Feldman, 2002; García-Montalvo \& Peiró, 2009; Maynard et al., 2006). For university graduates, OQ is a special concern because of the scarcity of qualified jobs in a labor market that has not evolved fast enough to meet graduates' job needs in times of economic crisis (CIPD, 2015; Vedder et al., 2013). Thus, in some countries the percentage of overqualified graduates is high. For instance, the Growth and Development Foundation (2014) reported that in Spain 33\% of young graduates were overqualified.

Research on OQ has focused on its consequences. OQ is negatively related to organizational commitment, wellbeing and job and career satisfaction, and positively related to job stress, counterproductive work behaviors, and turnover intentions (see for example Johnson \& Johnson, 1992, 1996; Liu et al., 2015; Luksyte et al., 2011; Maynard et al., 2006; McKee-Ryan \& Harvey, 2011). However, much less is known about the antecedents. This represents an important gap in the literature that needs to be addressed for both theoretical and practical reasons. From a theoretical perspective, research aimed at identifying antecedents of OQ can contribute to extending its nomological network and uncovering the mechanisms that link hypothetical antecedents and OQ. From a practical perspective, the identification of OQ determinants can be used to design strategies for preventing OQ.

Previous studies have suggested that social class is related to graduates' OQ (Tomlinson, 2012), but the specific mechanism that links both variables is not clear. Therefore, the goal of this study is to test a mediational model on the antecedents of OQ. We posit that social class is negatively related to OQ via social capital and tolerance towards OQ. We focus on these variables because previous (different) studies have suggested that social class is related to social capital (Pichler \& Wallace, 2009) and social capital is related to OQ (González-Romá et al., 2018) and tolerance towards OQ (Gamboa et al., 2016)

\subsection{Hypotheses}

We posit that the negative influence of graduates' social class on OQ is firstly transmitted via social capital (i.e., access to networks that provide individuals with interpersonal relationships that can offer career-related information and the possibility of identifying and fulfilling career opportunities; Seibert, Kraimer, \& Liden, 2001). Graduates belonging to higher classes have more resources to access formal social networks (e.g., clubs, voluntary and professional associations). Once in these formal social networks, they can establish informal contacts with other people linked to different network members. As a result, those graduates in upper classes will have more social capital (Pichler \& Wallace, 2009). Social capital will provide graduates with career-related information (e.g., job offers) and social 
contacts that should facilitate access to fitted (i.e., non-overqualified) jobs. Therefore, we hypothesize the following:

Hypothesis 1: Graduates' social class is negatively related to graduates' OQ via social capital, so that social class is positively related to social capital, and the latter is negatively related to OQ.

We posit that social class can also be negatively related to OQ through social capital and graduates' tolerance towards OQ. The latter is an attitudinal variable that refers to graduates' willingness to accept a job that requires less qualifications, education or skills than those s/he has. We propose that because graduates with low social capital are aware of the limitation this represents in order to get a fitted job, they will be more tolerant towards accepting an overqualified job as long as they get a job and do not go unemployed. Finally, because attitudes are antecedents of intentions, which in turn serve as antecedents for action (Judge \& Kammeyer-Mueller, 2012), those graduates with higher tolerance towards OQ should tend to have more overqualified jobs. Thus, we hypothesize the following:

Hypothesis 2: Graduates' social class is negatively related to graduates' OQ via social capital and tolerance towards OQ, so that social class is positively related to social capital, this variable is negatively related to tolerance towards $O Q$, and the latter is positively related to $\mathrm{OQ}$.

The two mediating mechanisms proposed in hour hypotheses are depicted in Figure 1.

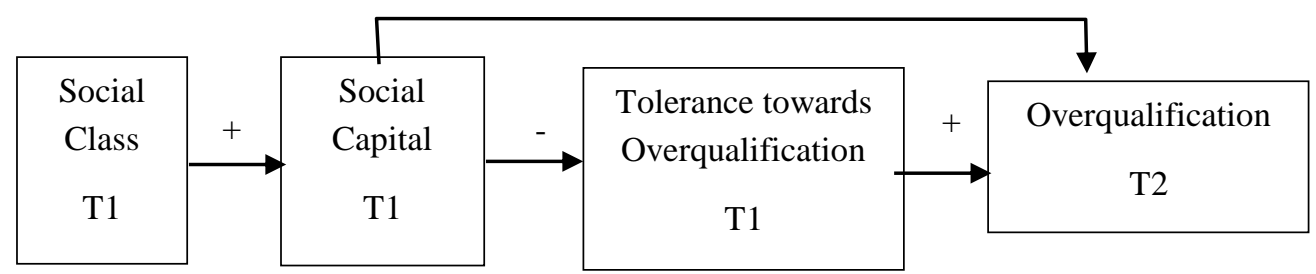

Figure 1. Research model

\section{Method}

\subsection{Participants and procedure}

Students from a public university in Spain $(\mathrm{N}=10,307)$ were contacted via email approximately two months before graduation (Time 1; T1). Those who voluntarily accepted to participate were informed that they would receive another questionnaire approximately six months after graduation (Time 2; T2). In exchange for their participation they received a free training course of their choice (leadership, team building, or time management). A total 
of 1,087 students responded to the survey at $\mathrm{T} 1$, and 503 of them also responded at $\mathrm{T} 2$. After discarding graduates who were unemployed at T2 or had obtained their jobs before graduation, 158 participants were kept. Finally, we discarded 14 participants that showed careless response patterns to two out of three instructed response items presented at each time. Thus, the final study sample was made of 144 graduates. Among them, $61.8 \%$ completed a bachelor degree and 38.2\% a Master degree. The average age was 24.9 (SD = 5.04 ) and $72.2 \%$ were female. Most of them (53.5\%) completed their degrees in social sciences, followed by health sciences $(29.2 \%)$, humanities $(11.1 \%)$, natural sciences and mathematics (4.8\%), and engineering (1.4\%).

\subsection{Measures}

Social class, social capital, and tolerance towards OQ were measured at T1. OQ was measured at T2. Specifically, social class was measured by asking students to choose among five possible ranks: 1 (lower) to 5 (upper). Social capital was measured by means of a 4-item scale based on González-Romá et al. (2018) (e.g., "I have an extensive network of friends who will help me to find job opportunities"'). Items were responded by means of a 6-point Likert scale (1. Totally Disagree, 6. Totally Agree). Cronbach's alpha was .87. Tolerance towards overqualification was measured by means of a 3-item scale (Gamboa et al., 2016) (e.g. "I would be willing to accept a job that requires less education than I have"). Items were responded by means of a 6-point Likert (1. Totally Disagree, 6. Totally Agree). Cronbach's alpha was .95. Finally, overqualification after graduation was measured by means of Maynard et al.’s (2006) 9-item scale (e.g., "My job requires less education than I have"). Items were responded by means of a 6-point Likert (1. Totally Disagree, 6. Totally Agree). Cronbach's alpha was .95.

\subsection{Analysis}

The mediating hypotheses involved in our model were tested using multiple regression by means of the PROCESS macro for SPSS (Hayes, 2015). Specifically, PROCESS estimated three regression models: 1) social capital was regressed on social class; 2) tolerance towards overqualification was regressed on social capital controlling for social class; and 3) overqualification was regressed on tolerance towards overqualification, controlling for both social class and social capital. In the last case, because there is evidence that the degree field, level of studies, gender and age are related to overqualification (Nunez \& Livanos, 2010; Prause \& Dooley, 2011; Weststar, 2011), we controlled for these variables. Following scholars' recommendations (e.g., Hayes, 2009; MacKinnon, 2008) the significance of the two hypothesized indirect effects [(Social class T1 $\rightarrow$ Social capital T1 $\rightarrow$ OQ T2) and (Social class T1 $\rightarrow$ Social capital T1 $\rightarrow$ Tolerance towards OQ T1 $\rightarrow$ OQ T2) were tested by means of bootstrapping. Specifically, 10,000 samples were bootstrapped. 
González-Romá, V.; Hernández, A.; Gamboa, J. P.; Tomás, I.

Table 1. Descriptive and correlations among variables in the research model.

\begin{tabular}{ccccccc}
\hline & & \multicolumn{5}{c}{ Correlations } \\
& Mean & SD & $\mathbf{1}$ & $\mathbf{2}$ & $\mathbf{3}$ & $\mathbf{4}$ \\
\hline Social Class (1) & 2.67 & .75 & -- & & \\
Social Capital (2) & 2.70 & 1.14 & $.16^{*}$ & $(.87)$ & & \\
Tolerance towards OQ (3) & 4.16 & 1.26 & $-.14^{*}$ & $-.30^{* *}$ & $(.95)$ & \\
OQ (4) & 3.73 & 1.50 & $-.14^{*}$ & $-.24^{* *}$ & $.26^{* *}$ & $(.95)$
\end{tabular}

Note. OQ: Overqualification. ${ }^{*} p<.05 ; * * p<.01$ (one-tailed tests). Scale reliabilities are shown in the diagonal

Table 2. Regression Analysis.

\begin{tabular}{llll} 
Equation & $\mathbf{B}$ & $\mathbf{S E}$ & $\mathbf{R}^{2}$ \\
\hline $\begin{array}{c}\text { 1. Social capital (T1) } \\
\text { Social class (T1 }\end{array}$ & $.24^{*}$ & .12 & $.15 \#$ \\
$\begin{array}{c}\text { 2. Tolerance Towards OQ (T1) } \\
\text { Social Class (T1) }\end{array}$ & -.17 & & $.31^{* *}$ \\
Social Capital (T1) & $-.31^{* *}$ & .13 &
\end{tabular}

3. Overqualification (T2)

$.50 * *$

$\begin{array}{lcr}\text { Age (T1) } & -.06 * * & .03 \\ \text { Health Sciences (T1) } & -1.05 & .40 \\ \text { Social Class (T1) } & -.20 & .16 \\ \text { Social Capital (T1) } & -.13 & .10 \\ \text { Tolerance towards OQ (T1) } & .19 * * & .09\end{array}$

\footnotetext{
Note. Regression coefficients are unstandardized; SE: Standard Error; ${ }^{\#} p<.10 ;{ }^{*} p<.05$; ${ }^{* *} p<.01$ (one-tailed tests for regression coefficients). For the sake of clarity, only control variables that show significant effects are included
}

\section{Results}

Correlational analysis showed that social class was negatively related to overqualification after graduation $(r=-.14 ; p<.05)$ (see Table 1$)$.

Regression analysis supported only one of the mediation chains hypothesized: the one proposed in Hypothesis 2 (Social class $\mathrm{T} 1 \rightarrow$ Social capital T1 $\rightarrow$ Tolerance towards OQ $\mathrm{T} 1 \rightarrow \mathrm{OQ}$ T2) (see Table 2). Specifically, social class was positively related to social capital 
$(B=.24 ; p<.05)$ which, in turn, was negatively related to tolerance towards OQ $(B=-.31$; $p<.01)$, which, in turn, was negatively related to OQ after graduation $(B=.19 ; p<.05)$. The indirect effect of social class on OQ via social capital and tolerance towards OQ (i.e. the product of the B coefficients involved in the mediating path) was .014. The bootstrapped $90 \%$ confidence interval ranged from -.049 to -.002. Thus, because this interval did not include zero, we concluded that the indirect effect was statistically significant.

Regarding Hypothesis 1, even if the bivariate relationship between social capital and OQ after graduation was negative and statistically significant $(r=-.24 ; p<.01)$ (see Table 1 ), when we regressed OQ on social capital, after partialing out the effects of the control variables as well the other antecedents of OQ, the relationship between OQ and social capital was not significant $(B=-.17, p>.05)$ (see Table 2). The corresponding indirect effect was.-.031, which was not statistically significant. Specifically, the $90 \%$ Confidence Interval ranged from -.108 to .002 .

\section{Discussion}

The results obtained in the present study supported one of the two mediating mechanisms proposed to explain the negative relationship between social class and OQ. This has important theoretical and practical implications that we discuss below.

\subsection{Theoretical implications}

We have uncovered one of the mechanisms by which social class is negatively related to university graduates' OQ. According to our results, social class is positively related to social capital, which in turn is negatively related to tolerance towards OQ, which in turn is positively related to $\mathrm{OQ}$. Our findings suggest that graduates in the lower social classes have a lower access to formal and informal social networks (Pichler \& Wallace, 2009), which results in a lower social capital. Because these graduates are aware of the limitation this represents in order to get a fitted job, they will be more tolerant towards OQ, which will translate into a trend to obtain jobs below their qualifications. These findings contribute to improving our understanding about the antecedents of graduates' OQ and the mechanisms linking social class and OQ, expanding its nomological network. Our study also contributes to filling a gap in the literature about the antecedents of OQ.

\subsection{Practical implications}

Our results suggest that increasing university graduates' social capital may be a way to decrease graduates' overqualification. In order to strengthen social capital, a number of strategies can be implemented. Graduates can attend professional meetings organized by professional and industry associations, join professional networks on the Internet, and 
inform their contacts (friends, acquaintances, and relatives) about their career goals (González-Romá et al., 2018). In addition, universities can organize meetings between students and recent graduates, on the one hand, and professional associations, on the other, as a way to facilitate contacts between the former and active professionals (González-Romá et al., 2018). Universities could also organize employment fairs in which firms go to university campuses to meet students and graduates and offer their job vacancies. These events represent a good opportunity to establish contacts with firms willing to hire university graduates.

\subsection{Limitations}

The present study has a number of limitations that we have to bear in mind when interpreting the results. First, all the variables were measured by self-reported scales and the data were provided by a single source (graduates). This might have inflated the observed relationships due to common-method variance. Second, although we collected data at two time points, the predictor and the two mediators were measured at Time 1. It would have been better to measure all these variables at different time points considering their causal order. Finally, the participants are not a representative sample, which limits the generalizability of our findings.

\subsection{Conclusion}

Despite these limitations, our study helps uncover one of the mechanisms explaining why social class is negatively related to university graduates' OQ.

\section{References}

Bolino, M. C., \& Feldman, D. C. (2000). The antecedents and consequences of underemployment among expatriates. Journal of Organizational Behavior, 21(8), 889911.

CIPD (2015). Unlocking workplace skills: What is the role of employers? Policy Report. London. Retrieved from https://www.cipd.co.uk/knowledge/work/skills/workforceskills-report

Gamboa, J.P.; Hernández, A. \& González-Romá, V. (2016) Higher education orientation and students' attitudes towards entering the labour market: the mediator role of employability Paper presented at the 31st International Congress of Psychology (ICP2016). Yokohama, Japan.

García-Montalvo, J. \& Peiró, J. M. (2009). Análisis de la sobrecualificación y la flexibilidad laboral [Overqualification and job flexibility]. Valencia, Spain: IVIE

González-Romá, V., Gamboa, J.P., \& Peiró, J.M. (2018). University Graduates' Employability, Employment Status, and Job Quality. Journal of Career Developement, Advance online publication. https://doi.org/10.1177/0894845316671607. 
Hayes, A. F. (2009) Beyond Baron and Kenny: Statistical Mediation Analysis in the New Millennium. Communication Monographs 76 (4): 408-420.

Hayes, A. F. (2015) An Index and Test of Linear Moderated Mediation. Multivariate Behavioral Research 50 (1): 1-22.

Johnson, G. J., \& Johnson, W. R. (1992). Subjective underemployment and psychosocial stress: The role of perceived social and supervisor support. Journal of Social Psychology, 132(1). 11-21.

Johnson, G. J., \& Johnson, W. R. (1996). Perceived overqualification and psychological well-being. Journal of Social Psychology, 136(4), 435-445.

Judge, T. A., \& Kammeyer-Mueller, J. D. (2012). Job attitudes. Annual Review of Psychology, 63, 341-367.

Liu, S., Luksyte, A., Zhou, L., Shi, J., \& Wang, M. (2015). Overqualification and counterproductive work behaviors: Examining a moderated mediation model. Journal of Organizational Behavior, 36(2), 250-271.

Luksyte, A., Spitzmueller, C., \& Maynard, D. C. (2011). Why do overqualified incumbents deviate? Examining multiple mediators. Journal of Occupational Health Psychology, 16(3), 279-296

MacKinnon, D.P. (2008). Introduction to Statistical Mediation Analysis. New York: Taylor \& Frances Group.

McKee-Ryan, F., \& Harvey, J. (2011). "I Have a Job, But...": A Review of Underemployment. Journal of Management, 37(4), 962-996.

Maynard, D. C., Joseph, T. A. \& Maynard, A. M. (2006), Underemployment, job attitudes, and turnover intentions. Journal of Organizational Behavior, 27(4), 509-536.

Nunez, I., \& Livanos, I. (2010). Higher education and unemployment in Europe: an analysis of the academic subject and national effects. Higher Education, 59(4), 475-487.

Pichler, F., \& Wallace, C. (2008). Social capital and social class in Europe: The role of social networks in social stratification. European Sociological Review, 25, 319-332.

Prause, J., \& Dooley, D. (2011). Youth Underemployment. In D. Maynard, \& D. Feldman (Eds.), Underemployment: psychological, economic, and social challenges (pp. 59-80). Springer: New York, NY.

Seibert, S., Kraimer, M., \& Liden, R. (2001). A Social Capital Theory of Career Success. The Academy of Management Journal, 44(2), 219-237.

Vedder, R., Denhart, Ch., \& Robe, J. (2013). Why Are Recent College Graduates Underemployed? University Enrollments and Labor-Market Realities. Washington, DC: Center for College Affordability and Productivity.

Weststar, J. (2011). A Review of Women's Experiences of Three Dimensions of Underemployment. In D. Maynard, \& D. Feldman (Eds.), Underemployment: psychological, economic, and social challenges (pp. 105-125) Springer: New York, NY. 